\title{
Bacillus subtilis muts mutL operon: identification, nucleotide sequence and mutagenesis
}

\author{
Francesca Ginetti, ${ }^{1}$ Marta Perego, ${ }^{1,2} \dagger$ Alessandra M. Albertini ${ }^{1}$ \\ and Alessandro Galizzi ${ }^{1}$ \\ Author for correspondence: Alessandro Galizzi. Tel: + 39382505548 \\ e-mail: albertini@ipvgen.unipv.it
}

1 Dipartimento di Genetica e Microbiologia, Università degli Studi di Pavia, 207 via Abbiategrasso, 27100 Pavia, Italy

2 Dipartimento

Farmaceutico, Università degli Studi di Parma, Italy

\begin{abstract}
The Bacillus subtilis muts and mutl genes, involved in the DNA mismatch repair system, have been cloned and characterized. From sequence analysis the two genes appear to be organized in a single operon, located immediately downstream of the cotE gene (approximately $150^{\circ}$ on the genetic map). The deduced Muts protein is $49 \%$ identical to HexA and MutL is $46 \%$ identical to HexB of Streptococcus pneumoniae. Deletion of both muts and mutL resulted in an increase in the frequency of spontaneous mutations and abolished the marker effect observed in transformation. The expression of the mut operon was studied with the use of a mutSL-lacZ transcriptional fusion. An increase in expression was observed during late exponential growth.
\end{abstract}

Keywords: Bacillus subtilis, mut operon, DNA repair, mutagenesis

\section{INTRODUCTION}

The genetic integrity of bacterial genomes is guaranteed by, among other systems, the mismatch repair machinery, acting on mispaired regions derived from replication errors or recombination intermediates. Biosynthetic mistakes generated during chromosomal replication are eliminated by the mutSHL excision repair system (Modrich, 1994). In Escherichia coli and Salmonella typhimurium, mutation is avoided by discrimination between the newly synthesized DNA strand and the template DNA strand, the latter being tagged by dam-dependent methylation (Modrich, 1991). A second source of base mispairing is represented by the generation of heteroduplex DNA ensuing from genetic recombination. The dedicated mismatch repair system has been thoroughly described in Streptococcus pneumoniae and depends on the products of the genes bex $A$ and bexB (Claverys \& Lacks, 1986). In this case the discrimination between the endogenous strand and the incoming one, seems to be nick-directed and targeted to the incoming strand of the

+Present address: The Scripps Research Institute, Division of Cell Biology, La Jolla CA92037, USA.

Abbreviations: i.s., identity score; PY, Penassay Broth; SM, Schaeffer's sporulation medium; Ap, ampicillin; $\mathrm{Cm}$, chloramphenicol; Em, erythromycin; Rf, rifampicin.

The GenBank accession number for the nucleotide sequence reported in this paper is U27343. heteroduplex by the presence of strand discontinuities (Prudhomme et al., 1991).

The Mut and Hex systems both involve long excision tracts and even if the initial event is different (the presence of hemimethylated sites in the case of Mut, the availability of single strand ends in the case of Hex), the two mechanisms are very similar and functionally equivalent. In fact the Mut repair pathway has been shown to be involved in maintaining the natural barrier to interspecific recombination between $E$. coli and Sal. typhimurium (Rayssiguier et al., 1989). The mismatch recognition functions of MutS and MutL of E. coli also act to prevent homologous recombination between duplicated, diverged sequences (Petit et al., 1991) and a possible role of these two repair proteins in RecA-catalysed strand exchange has been suggested by in vitro experiments (Worth et al., 1994). Cloning and sequencing of the genes involved in the Hex and Mut systems of E. coli, Sal.typhimurium, Strep. pneumoniae and Azotobacter vinelandii, confirmed the functional similarities. The MutS and HexA proteins are highly similar, and so are MutL and HexB (Connoly \& Winkler, 1992; Haber et al., 1988; Le et al., 1993; Mankovich et al., 1989; Prudhomme et al., 1989, 1991; Priebe et al., 1988; Schlensong \& Boeck, 1991). Negative complementation conferred by the expression in E. coli of the Strep. pneumoniae HexA function confirmed their common evolutionary origin (Prudhomme et al., 1991).

Functions similar to the bacterial components of the mismatch repair machinery, have been identified in yeast 
Table 1. B. subtilis strains used in this study

\begin{tabular}{|c|c|c|}
\hline Strain & Genotype* & Source or reference $t$ \\
\hline PB19 & Prototropb & SB 19, E. W. Nester \\
\hline PB168 & $\operatorname{trp} C 2$ & \\
\hline PB1679 & ilv $A 1 \operatorname{met} B 5 \operatorname{nrd} A$ & E3113, D. Karamata \\
\hline PB1701 & $\operatorname{trp} C 2$ met $B 4$ & GSY228, C. Anagnostopoulos \\
\hline PB1814 & dnaF69 gln $A 100$ & A. Galizzi \\
\hline PB1831 & $\operatorname{trp} C 2$ phe $A 1$ & JH642, J. Hoch \\
\hline PB1841 & $\operatorname{trpC} 2$ cotE: : pLZ100-HP cat & PB168 tf $\neq$ with pLZ100-HP \\
\hline PB1843 & $\operatorname{rec} A 260$ metB5 $S P \beta(-) \operatorname{trp} C 2 \times \sin -1 \mathrm{erm}$ & BGSC1A746 \\
\hline PB1856 & $\operatorname{trpC} 2$ pbe.A1 $\triangle$ mutSL::cat & This work \\
\hline PB1868 & $\operatorname{trp} C 2$ ilv $C 1$ & GSY111, C. Anagnostopoulos \\
\hline PB1869 & $\operatorname{trpC} 2$ ilvC1 $\triangle m u t S L:: c a t$ & PB1868 tf $\ddagger$ with PB1856 \\
\hline PB1870 & $\operatorname{trp} C 2$ metB4 $\Delta$ mutSL::cat & PB1701 tf $\ddagger$ with PB1856 \\
\hline PB5179 & $\operatorname{trpC} 2$ mutL: :pFG2792 erm & PB168 tf $\ddagger$ with pFG2792 \\
\hline PB5180 & $\begin{array}{l}\operatorname{trpC} 2 \cot E:: \mathrm{pLZ} 100-\mathrm{HP} \text { cat } \\
\text { mutL::pFG2792 erm }\end{array}$ & PB1841 tf + with PB5179 \\
\hline PB5207 & $\operatorname{trp} C 2$ phe $A 1$ mutSL: : lac $Z$ cat & PB1831 tf $\neq$ with pFG2783S \\
\hline PB5211 & $\begin{array}{l}\text { rec } A 260 \text { metB5 SP } \beta(-) \operatorname{trp} C 2 \times \text { in }-1 \mathrm{erm} \\
\text { mutSL: : lac } \mathrm{cat}\end{array}$ & PB1843 tf $\neq$ with pFG2783S \\
\hline
\end{tabular}

* cat and erm are the determinants for $\mathrm{Cm}^{\mathrm{R}}$ and $\mathrm{Em}^{\mathrm{R}}$, respectively.

†BGSC, Bacillus Genetic Stock Center, Ohio, USA; E. W. Nester, Stanford, USA; D. Karamata, Lausanne, Switzerland; C. Anagnostopoulos, Gif-sur-Yvette, France; A. Galizzi, this laboratory; J. Hoch, La Jolla, USA.

$\ddagger$ Constructed by transformation with either plasmid or chromosomal DNA.

Table 2. Plasmids used in this study

\begin{tabular}{|c|c|}
\hline Plasmid & Description (source or reference) \\
\hline \multicolumn{2}{|l|}{ Vectors } \\
\hline pJH101 & Ap Tc Cm; integrative vector (Ferrari et al., 1993) \\
\hline pJM103 & Ap Cm; integrative vector (Perego, 1993) \\
\hline pJM105A & Ap $\mathrm{Cm}$; integrative vector (Perego, 1993) \\
\hline pJM109 & Em; integrative vector (Perego, 1993) \\
\hline pDIA5304 & Ap Cm; integrative vector, used for plasmid walking (Glaser et al., 1993) \\
\hline $\mathrm{pDH} 32$ & $\begin{array}{l}\text { Ap } C m \text {; vector used to construct lac } Z \text { transcriptional fusions and } \\
\text { recombine into the chromosome at amyE (Shimotsu \& Henner, 1986) }\end{array}$ \\
\hline \multicolumn{2}{|c|}{ Other plasmids } \\
\hline $\mathrm{pLZ} 100$ & $\begin{array}{l}\text { Clone of cotE ( } 2 \mathrm{~kb} \text { HindIII fragment) in pBR322 (gift of L. Zheng, } \\
\text { Cambridge, USA) }\end{array}$ \\
\hline pLZ100-HP & $\begin{array}{l}0.6 \mathrm{~kb} \text { HindIII-HpaII fragment from pLZ100, upstream of cotE, cloned } \\
\text { into pJH101 }\end{array}$ \\
\hline pFG2752 & $5.3 \mathrm{~kb} \mathrm{Bg} / \mathrm{II}$ chromosomal fragment cloned into pJM103 \\
\hline pFG2764A & $0.5 \mathrm{~kb} H i n \mathrm{dIII}-\mathrm{Bg} / \mathrm{II}$ fragment from $\mathrm{pFG} 2752$ cloned into pDIA5304 \\
\hline pFG2767 & $\begin{array}{l}2.5 \mathrm{~kb} \text { HindIII-SacI fragment in pDIA } 5304 \text {, obtained by SacI digestion } \\
\text { and ligation of chromosomal DNA from transformants with pFG2764A }\end{array}$ \\
\hline pFG2769 & $1.5 \mathrm{~kb} \mathrm{Bg} / \mathrm{II}$ fragment from pFG2767 cloned into pJM103 \\
\hline pFG2771 & $\begin{array}{l}3.7 \mathrm{~kb} B g / \mathrm{II}-S p h \mathrm{I} \text { fragment in pJM103, obtained by } S p h \mathrm{I} \text { digestion and } \\
\text { ligation of chromosomal DNA from transformants with pFG2769 }\end{array}$ \\
\hline pFG2783S & $\begin{array}{l}333 \text { bp EcoRI-Bam HI fragment obtained by PCR, cloned in } \mathrm{pDH} 32 \text {, } \\
\text { containing the mutSL promoter }\end{array}$ \\
\hline pFG2791 & $\begin{array}{l}\text { pJM105A derivative, containing a } 687 K p n \mathrm{I}-\text { ClaI fragment (mutS start) } \\
\text { and a } 419 \text { bp Pst } \mathrm{I}-\text { BamHI fragment (mutL end) at the sites of the cat } \\
\text { cassette; used to make } \Delta m u t S L: \text { : cat }\end{array}$ \\
\hline pFG2792 & $\begin{array}{l}\text { PJM109 derivative, containing the Pst } \mathrm{I}-\text { Bam HI fragment from pFG2791, } \\
\text { corresponding to the end of mut L; used for genetic mapping }\end{array}$ \\
\hline
\end{tabular}


(a)
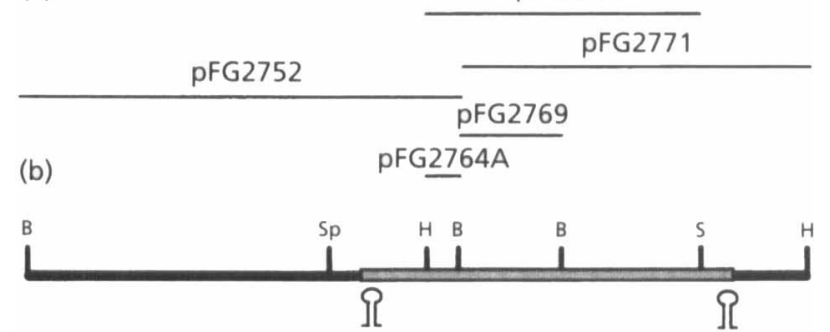

(c)
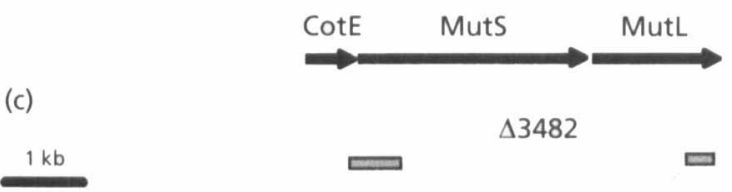

$1 \mathrm{~kb}$

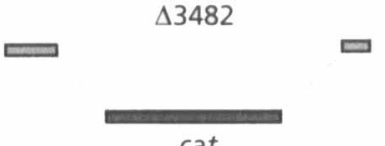

cat

Fig. 1. Map of the mutSL operon. (a) Bars represent the inserts in the indicated plasmids. (b) Restriction endonuclease cleavage sites are represented as follows: B, Bg/II; H, HindIII; S, SaCl; Sp, $S p h l$. Only relevant sites are reported. The lightly shaded region indicates the sequence described in this paper. The position of two putative terminators is indicated by hairpins. The ORFs are represented by arrows; the direction of transcription is toward the terminus of DNA replication. (c) $\Delta 3482$ indicates the extent of the deletion obtained by double cross-over gene replacement obtained upon transformation of the linearized plasmid pFG2791. cat is the $\mathrm{Cm}^{\mathrm{R}}$ determinant cassette.

(Kramer et al., 1989; Reenan \& Kolodner, 1992) and in human cells (Fishel et al., 1993; Leach et al., 1993; Nicolaides et al., 1994; Papadopoulos et al., 1994). In yeast, evidence has been obtained that MSH2 or PMS1 functions (homologues of MutS and MutL) can act as a system of control of symmetric heteroduplex length during recombination (Alani et al., 1994). The human MutS homologue (hMSH2) and the three human MutL homologues (hMLH1, hPMS1 and hPMS2) are involved in a DNA surveillance defect in cancer cells: loss of mismatch repair proficiency is responsible for the common cancer predisposition syndrome known as HNPCC (hereditary nonpolyposis colorectal cancer) (Bronner $e t$ al., 1994; Leach et al., 1993; Nicolaides et al., 1994; Papadopoulos et al., 1994).

In this work we report the cloning, sequence determination and functional characterization by targeted mutagenesis of the Bacillus subtilis muts and mutL genes. The two genes are organized in an operon: we present preliminary data on the regulation of expression, in particular during the transition to stationary phase.

\section{METHODS}

Media. B. subtilis was grown in Schaeffer's sporulation medium (SM) (Schaeffer et al., 1965) or Penassay Broth (PY; Difco). Antibiotics were used at the following concentrations: ampicillin (Ap), $100 \mu \mathrm{g} \mathrm{ml}^{-1}$; chloramphenicol $(\mathrm{Cm}), 5 \mu \mathrm{g} \mathrm{ml} \mathrm{m}^{-1}$;

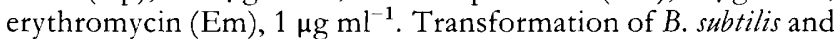
PBS1-mediated transduction were performed according to Hoch et al. (1967). Non-temperature sensitive $\left(\mathrm{ts}^{+}\right)$recombinants were selected on nutrient agar plates incubated at $47^{\circ} \mathrm{C}$.
Strains, plasmids and PCR. Standard E. coli strains were used for cloning (Sambrook et al., 1989). The B. subtilis strains used are listed in Table 1 , and the plasmids in Table 2. To evaluate the expression of the mutSL operon, we constructed a mut $S-l a c Z$ transcriptional fusion that contained $330 \mathrm{bp}$ from the end of $\cot E$ to codon 50 of mutS. The fragment was obtained by PCR performed with chromosomal DNA derived from strain PB168 $(\operatorname{tr} p C 2)$. The forward primer (FG1001) was a 26-mer with the sequence 5' GGAATTCCGGAGTTTTTAG'TGGGAGA $3^{\prime}$ (the underlined bases correspond to the end of $\cot E$ ). The $5^{\prime}$ part of the primer was designed to contain an EcoRI recognition site. The backward primer (FG1002) was a 26-mer derived from mutS and with a BamHI recognition site at its 5(end. The sequence of FG1002 was $5^{\prime}$ CGGATCCGCACCGCCGTCTCTGCTCG 3' (the underlined bases correspond to the sequence derived from mutS). PCR was run for 30 cycles with the following parameters: denaturation, $3 \mathrm{~min}$ at $93^{\circ} \mathrm{C}$ for the first cycle and $1 \mathrm{~min}$ at $92^{\circ} \mathrm{C}$ thereafter; annealing, $1 \mathrm{~min}$ at $51^{\circ} \mathrm{C}$; extension, $15 \mathrm{~s}$ at $72^{\circ} \mathrm{C}$. The PCR product was purified by PAGE and electroelution, then digested with EcoRI and $\mathrm{BamHI}$ and cloned into pDH32 (Shimotsu \& Henner, 1986) upstream of lac $Z$. The plasmid with the fusion was designated pFG2783S (Table 2). It was linearized and used to transform strains $\mathrm{PB} 1831$ and PB1843 selecting for $\mathrm{Cm}^{\mathrm{R}}$. Double crossover events that resulted in the introduction of the mut - lac $Z$ fusion at the amyE locus caused an $\mathrm{Amy}^{-}$phenotype.

A strain with a deletion of mutS and $m u t L$ was constructed by gene replacement by a double cross-over and insertion of a $\mathrm{Cm}^{\mathrm{R}}$ determinant. To this purpose a $687 \mathrm{bp}$ fragment containing the mutS promoter and the first $572 \mathrm{bp}$ of the coding sequence was produced by PCR on chromosomal DNA. The forward primer (FG1003) was a 26-mer with the sequence 5' GGGGTACC ACAGTACCCCCAAGTCTC 3' (the underlined bases correspond to the mut $S$ sequence, preceded $5^{\prime}$ by a $K p n I$ recognition site). The backward primer (FG1004), was a 26-mer with the sequence 5' CCATCGATACCGCACCGCTCTCTCAG 3', with a ClaI recognition site at its $5^{\prime}$ end. PCR was run for 35 cycles with the following parameters; denaturation, $3 \mathrm{~min}$ at $93{ }^{\circ} \mathrm{C}$ for the first cycle and $1 \mathrm{~min}$ at $92{ }^{\circ} \mathrm{C}$ thereafter; annealing, $1 \mathrm{~min}$ at $53{ }^{\circ} \mathrm{C}$; extension, $45 \mathrm{~s}$ at $72{ }^{\circ} \mathrm{C}$. The PCR product was purified as above and cloned into pJM105A restricted with $K p n$ I and ClaI. The downstream fragment of $418 \mathrm{bp}$, corresponding to the end of mutL, was also obtained by PCR with the following primers: FG1005, 5' AACTGCAGCTGACGTT CCACTACTCC $3^{\prime}$, with a Pst I restriction site at its $5^{\prime}$ end, and FG1006, 5' CGGGATCCTACCACCCCCGCTACATC3', with a BamHI site at its $5^{\prime}$ end. PCR was run for 30 cycles with the following parameters; denaturation, $3 \mathrm{~min}$ at $93{ }^{\circ} \mathrm{C}$ for the first cycle and $1 \mathrm{~min}$ at $95^{\circ} \mathrm{C}$ thereafter; annealing, $1 \mathrm{~min}$ at $52^{\circ} \mathrm{C}$; extension, $20 \mathrm{~s}$ at $72^{\circ} \mathrm{C}$. The purified PCR product was digested with PstI and BamHI and cloned in the pJM105A derivative containing the upstream fragment. The plasmid containing the two fragments on either side of cat, $\mathrm{pFG} 2791$, was linearized and transformed into strain PB1831 selecting for $\mathrm{Cm}^{\mathrm{R}}$.

$\boldsymbol{\beta}$-Galactosidase assays. All assays were performed on triplicate samples and the values were averaged. $\beta$-Galactosidase specific activity is expressed as Miller units (mg protein) ${ }^{-1}$ calculated as described previously (Albertini \& Galizzi, 1990).

DNA sequencing. T7 DNA polymerase (Pharmacia LKB) was used to sequence double-stranded plasmid DNA. The sequence of both strands was determined using custom-made primers. Oligonucleotides were synthesized by the phosphoramidite method by means of a Cyclon Plus DNA synthesizer (Milligen Biosearch). 
(a)

B.s. MutS

S.p. HexA

A.v. Muts

E.c. MutS

S.t. MutS

S.c. $\mathrm{MSH} 2$

H.s. MSH2

M.m. Rep3

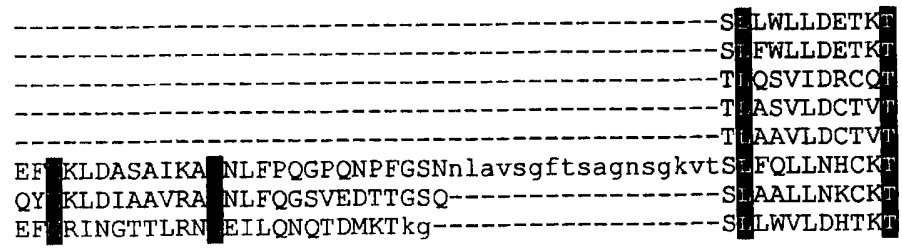

B.s. MutS

S.p. HexA

A.v. Muts

E.c. MutS

S.t. MutS

S.C. MSH2

H.S. MSH2

M.m. Rep3

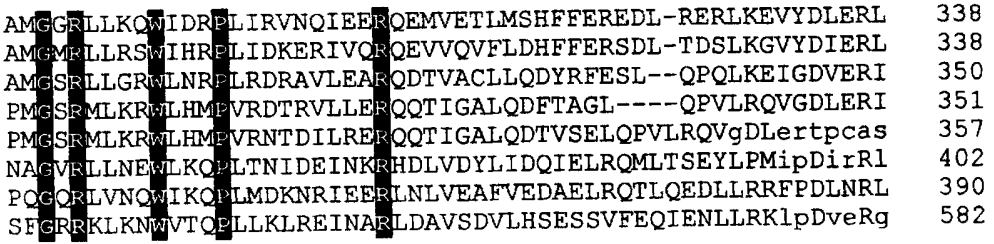

(b)

B.s. Muts

S.p. HexA

A.v. MutS

E.c. MutS

S.t. MutS

S.c. $\mathrm{MSH} 2$

H. MSH2

M.m. Rep3

ALQC-----FAT ISENRHYTKPEFSK-----DEVEVIEGRHP-VVEKVMDSQEYV LQSL----- AVVAETQHLIRPEFGDD-----SQIDIRKGKHA-VVEKVMGAQTY I LANL -----ERALNLDFNRPRFVEE--.--PCLRIRQGRH P-VVEOVLDT--PF LVINL - -..--ERAYTLNYTCPTFIDK-.-.--PGIRITEG H P-VVEOVLNEPFIA

LVNL -----ERAWTLNYTCPTFTDK-----PGIRITEGR HP-VVEQVLNEPFIA

IASH ht SS YAP I PY IRPKLHPMDSE-----RRTHLISSR HP-VLEMQDD-ISFI

VVSF -- - HVSngapvoyvrpai lekgggRIILKA-SPHACVEVODE--IAFI IFSL-----AKVAKQGNYCRPTLQEE-----KKI I I KNGRH P-MIDVLLGEQDQF

B.s. MutS

S.p. HexA

A.v. Muts

E.c. Muts

S.t. MutS

S.c. MSH2

H.S. MSH2

M.m. Rep3

PNNCMM-GDNRQMLLI PNT IQM-AEDTSIQLV VANDLELDDNTRMI I I NPLNLS--PQRRMLII NPLNLS--PQRRML I I SNDVTLESGKGDFL.I I

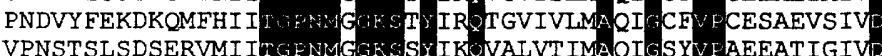

B.s. Muts

S.p. HexA

A.v. Muts

E.c. Muts

S.t. MutS

S.c. MSH2

H.s. MSH2

M.m. Rep3

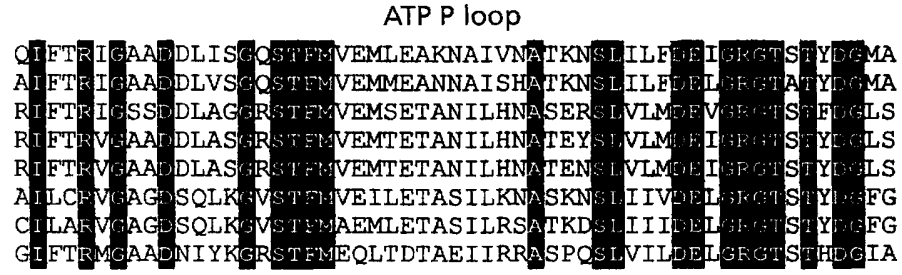

B.s. Muts

S.p. HexA

A.v. Muts

E.c. Muts

S.t. MutS

S.c. MSH2

H.s. MSH2

M.m. Rep3
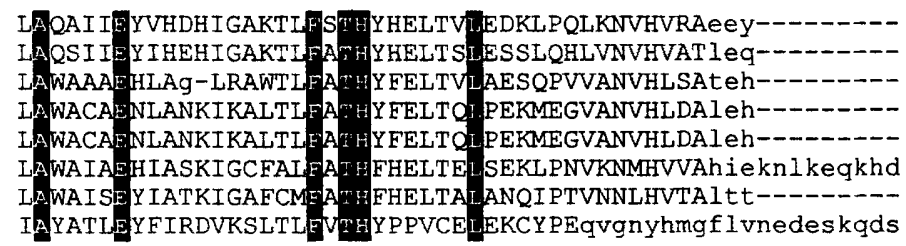

B.s. MutS

S.p. HexA

A.v. MutS

E.c. MutS

S.t. MutS

S.c. MSH2

H.s. MSH2

M.m. Rep3

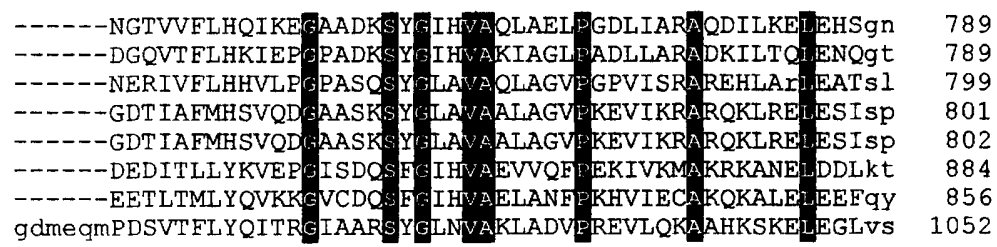

Fig. 2. Multiple alignment of the amino acid sequence of MutS proteins. Shaded boxes indicate universally conserved amino acids. Two stretches ( $a$ and $b$ ) of significant similarity are shown. The conserved signature of the ATP binding site $(P$ loop) is indicated in (b). Species abbreviations used and the DNA or protein sequence accession numbers are: $B$. s., $B$. subtilis (U27343); S.p., Strep. pneumoniae (P10564); A.v., A. vinelandii (P27345); E.c., E. coli (P23909); S.t., Sal. typhimurium (P10399); S.c., Saccharomyces cerevisiae (P25847); H.s., Homo sapiens (U03911); M.m., Mus musculus (P13705). 


\section{RESULTS AND DISCUSSION}

\section{Cloning the B. subtilis mutS and mutL genes}

As part of an international project to sequence the $B$. subtilis genome, we cloned three overlapping fragments in the $\cot E$ region at $150^{\circ}$ on the chromosome. The first fragment (present in plasmid pFG2752) was obtained by cloning $\mathrm{Bg} / \mathrm{II}$-cut chromosomal DNA in the integrative vector pJM103 (Perego, 1993) and hybridizing with a $2 \mathrm{~kb}$ HindIII probe obtained from the cotE-carrying plasmid pLZ100 (Fig. 1). A pFG2752 subclone was constructed in the integrative plasmid pDIA5304 (Glaser et al., 1993), which, as for pJM103, confers $\mathrm{Cm}^{\mathrm{R}}$ upon integration into the $B$. subtilis chromosome, giving rise to plasmid pFG2764A (Fig. 1 and Table 2). The chromosome walking technique was used to clone additional fragments further downstream of $\cot E$. In a first step, $S_{a c} \mathrm{I}$ restriction and plasmid rescue carried out on chromosomal DNA containing integrated $\mathrm{pFG} 2764 \mathrm{~A}$ resulted in plasmid pFG2767. Its derivative $\mathrm{pFG} 2769$ was used for an additional walking step, generating plasmid pFG2771.

The nucleotide sequence of the cloned region showed the presence of cotE and, downstream of it, two ORFs of 2577

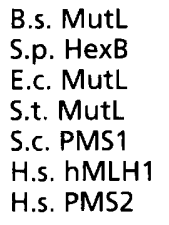

B.s. MutL S.p. HexB E.C. MutL S.t. MutL S.c. PMS1 H.S. hMLH1 H.s. PMS2 B.s. MutL
S.p. HexB
E.C. MutL
S.t. MutL
S.C. PMS1
H.S. hMLH1
H.S. PMS2
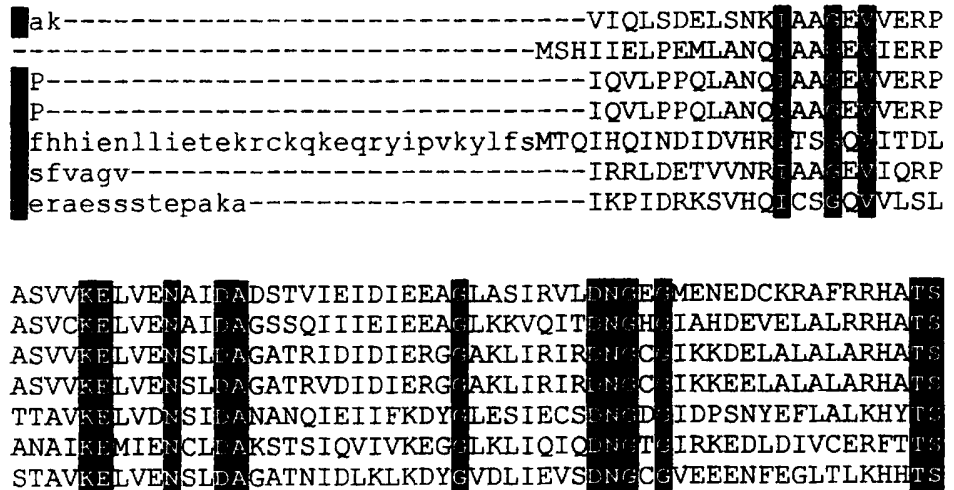
STAVKELVENSLDAGATNIDLKLKDYGVDLIEVSUNGCGVEEENEEGLTLKHHTS
IASVSHLEITTSTGEGAG--TKLVLQGGNIIS IASVSVLTLLTAVDGASHG-TKLVARGGEVEE ISSVSRLTLTSRTAEQQEAWQAYAEGRDMNVT ISSVSRLTLTSRTAEQAEAWQAYAEGRDMDVT LCGIAKLSVITTTSPPKAD-KLEYDMVGHITS I SHVAHVT ITTKTADGKCAYRASYSDGKLKAP CALSDVT ISTCHASAKVGTRIMFDHNGKI IQ
24

24

23

23

55

35

79

79

78

78

110

90

132

133

133

133

164

138 145

\section{6}

187

187

187

219

191

200

B.s. MutL

S.p. HexB

E.C. MutL

S.t. MutL

S.c. PMS1

H.s. hMLH1

H.s. PMS2

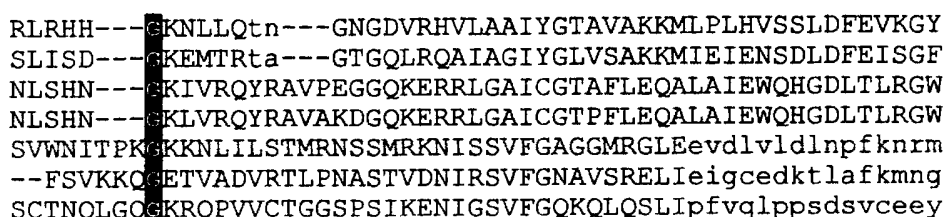

235

236

239

239

274

244

255

B.s. MutL
S.p. HexB
E.c. MutL
S.t. MutL
S.c. PMS1
H.s. hMLH

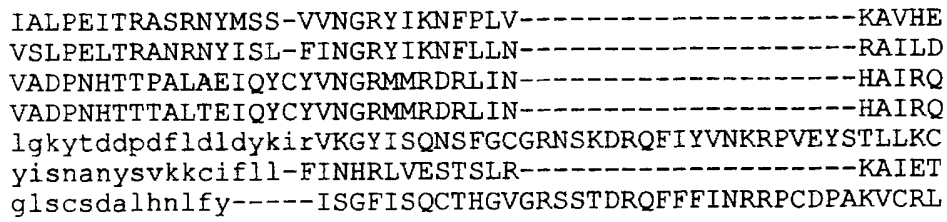

Fig. 3. Multiple alignment of the amino acid sequence of MutL proteins. Shaded boxes indicate universally conserved amino acids. Only the amino terminus of the proteins is shown. Species abbreviations used and the DNA or protein sequence accession numbers are: B.S., B. subtilis (U27343); S.p., Strep. pneumoniae (P14161); E.C., E. coli (P23367); S.t., Sal. typhimurium (P14160); S.c., Sacch. cerevisiae (P14242); H.s. hMLH1, H. sapiens (P23367); H.s. hPMS2, H. sapiens (2017356B). 
(a)

(a)

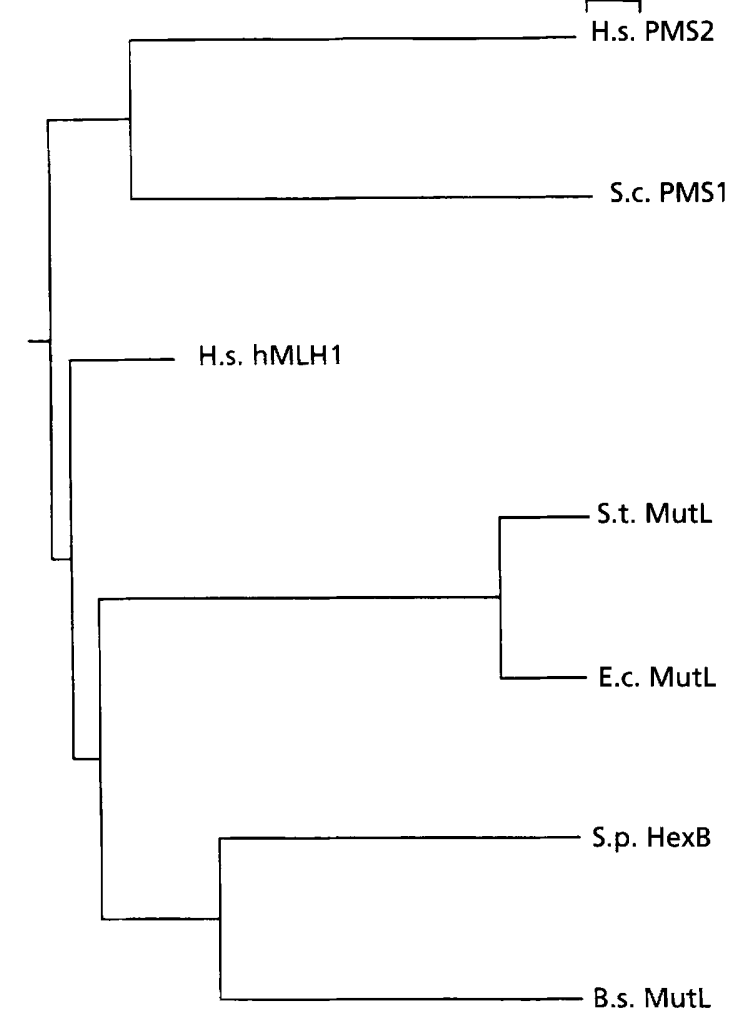

(b) $\quad 0.039$
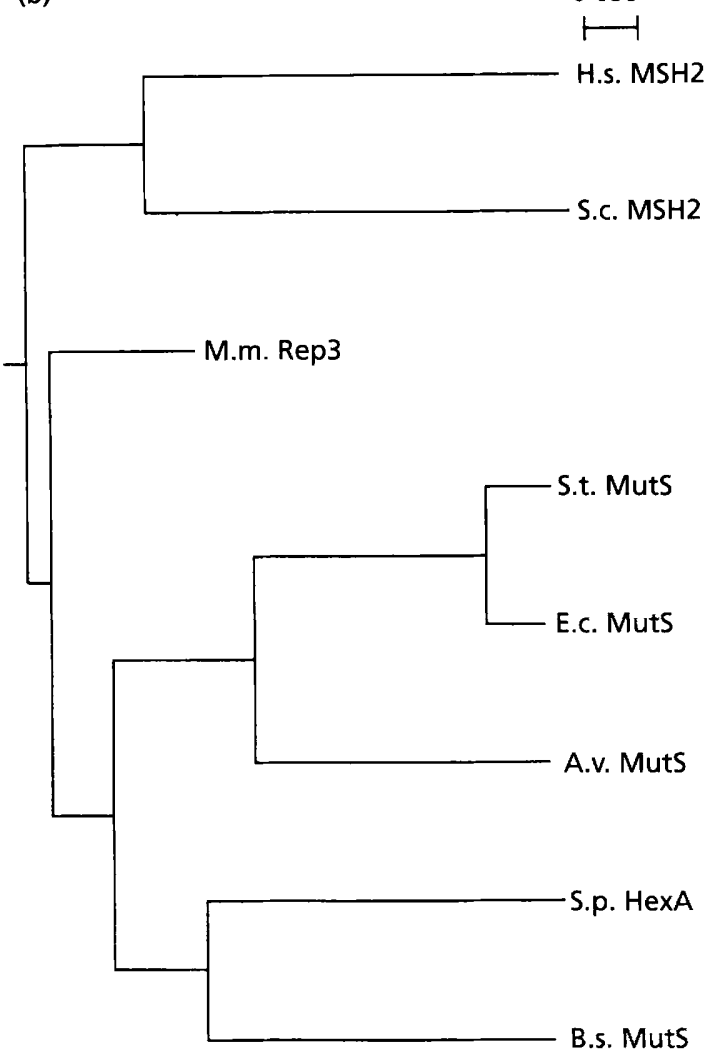

Fig. 4. Phylogenetic analysis of MutS (a) and MutL (b) proteins graphically displayed with the NJPLOT software of M. Gouy (University of Lyon, France). The scale bars indicate the distances as calculated from the multiple alignment (Thompson et al., 1994). Abbreviations are defined in the legends to Figs 2 and 3.

and $1884 \mathrm{bp}$, respectively. The first ORF starts $151 \mathrm{bp}$ from the end of cotE. The ATG start codon is preceded by a sequence that could act as a ribosome binding site. $\AA$ search for transcription control signal sequences in the intercistronic region showed the presence downstream of a hairpin loop with a $\Delta G$ of $-110 \mathrm{~kJ} \mathrm{~mol}^{-1}$, a putative terminator of $\cot E$ and a potential $\sigma^{\mathbf{A}}$-dependent -10 sequence, perfectly matching the consensus. The putative -35 region was hardly detectable. The second ORF starts $16 \mathrm{bp}$ after the stop codon of the first one. No terminator site or recognizable promoter was identified between the two ORFs, suggesting that they belong to the same operon. The operon is followed by a strong factor-independent transcription termination signal $\left(\Delta G-140.6 \mathrm{~kJ} \mathrm{~mol}^{-1}\right)$.

With the FASTA (Pearson, 1990) and BLAST programs (Altschul et al., 1990) we compared the two deduced protein sequences to other proteins available in the data banks. For the 2577 bp ORF, significant homology was found to Strep. pneumoniae mismatch protein Hex A (49.4\% identity score, i.s.), to $A$. vinelandii, E. coli and $S a l$. typhimurium mismatch protein MutS $(38 \cdot 4,40 \cdot 2$ and $39 \cdot 4 \%$ i.s., respectively), and to yeast MSH2 and human hMSH2 (stretches with 31.9 and $32.4 \%$ i.s., respectively). Multiple alignment revealed a significant degree of similarity over the whole polypeptide sequence with the prokaryotic homologue, particularly with HexA; with the eukaryotic homologue the similarity was particularly striking in the last third of the polypeptides starting from the ATPase consensus site as shown in Fig. 2. The 1884 bp ORF was found to be homologous to Strep. pneumoniae HexB (45.6\% i.s.), to E. coli and Sal. typhimurium MutL (30.7 and $30.1 \%$ i.s., respectively) and to yeast and human DNA mismatch repair proteins PMS1, hMLH1 and PMS2 (stretches with $28 \cdot 1,32 \cdot 7$ and $30 \cdot 1 \%$ i.s., respectively). As for MutS, the B. subtilis polypeptide is similar to the prokaryotic counterparts over the whole sequence, whereas the similarity to the eukaryotic homologues is restricted to the amino-terminal half (Fig. 3).

The high level of identity observed for both deduced proteins led us to name the genes mutS and mutL, respectively. The evolutionary relatedness, as suggested by comparison performed with CLUSTALPPC (Thompson $e t$ al., 1994) and NJPLOT for the construction of phylogenetic trees (Fig. 4), suggests a common evolutionary origin for the prokaryotic and eukaryotic mismatch recognition functions of the Mut pathway. As expected, the Grampositive and Gram-negative bacteria form two different branches of the tree.

As discussed above, the organization of mut $S$ and $m u t L$ in B. subtilis strongly suggests that the two genes are part of a single operon. Among the bacterial systems described, this is the first instance of such an organization that could be advantageous to the cell leading to the co-ordinate 
expression of two proteins involved in mismatch repair. The hypothesis of common regulation for the Strep. pneumoniae mismatch recognition functions $\mathrm{HexA}$ and HexB, was first proposed by Prudhomme et al. (1989) following the observation of conserved sequences in the -10 promoter and Shine-Dalgarno region of the two genes. As suggested by the authors, the co-ordinate expression of the MutS and MutL functions could be of special importance, not only to avoid the mutator effect of unbalanced production of one of the two elements, but also in view of the constraints imposed by the differentiated stage of competence to transformation. Such a coordinate expression seems to be obtained in Strep. pneumoniae by the presence of a common putative regulatory sequence upstream of the two genes and in $B$. subtilis by the clustering of mutS and mut $L$ in a single operon. Nevertheless inspection of the B. subtilis sequence upstream of mutS showed good homology with the sequences present at the promoters of bex $A$ and bex $B$ genes (Prudhomme et al., 1989) (data not shown). If the observed sequence is indeed involved in regulation, the presence in the mutSL operon of B. subtilis may indicate that its expression is co-ordinately regulated with the expression of other, as yet undetected, genes or operons.

\section{Genetic map}

The cotE gene has been mapped by PBS1-mediated transduction between pyrD1 and thy $A 1$, at about $150^{\circ}$ on the genetic map (Zheng et al., 1988). To narrow the location of $\cot E$, we performed transductions with PBS1 lysates from PB1841 (cotE-cat) used to transduce to ts ${ }^{+}$ two temperature-sensitive $\operatorname{pol} C$ and $n r d A$ mutants (PB1814 and PB1679, respectively). Two-factor crosses indicated that $\cot E$ (cat) had a linkage of $70 \%$ to polC and $50 \%$ to $n r d A$. To obtain information about the direction of transcription, we did a three-factor cross with $\cot E$-cat, mutL-erm and polC. Strain PB1814 was transduced to ts $^{+}$ with a PBS1 lysate from PB5180 (cotE-cat, mutL-erm). cat was co-transduced with polC in 56 of 110 transductants; most $\mathrm{Cm}^{\mathrm{R}}$ transductants were also $\mathrm{Em}^{\mathrm{R}}$ (51 of 56), and only five were $\mathrm{Em}^{\mathrm{S}}$. No $\mathrm{Cm}^{\mathrm{S}} \mathrm{Em}^{\mathrm{R}}$ transductants were obtained, indicating that the gene order is polC-cotEmut $L$. Thus the direction of transcription of $\cot E$ and mutSL is toward the terminus of DNA replication.

\section{Construction of a mut $S L$ deletion mutant}

To prove the effective role of the two genes in the repair process, we constructed a deletion mutant in which both MutS and MutL could not be synthesized. Two fragments, obtained by PCR amplification, were cloned on either side of the $\mathrm{Cm}^{\mathrm{R}}$ determinant of the vector $\mathrm{pJM} 105 \mathrm{~A}$ (Perego, 1993). The first fragment, 687 bp long, contained the muts promoter and the first $572 \mathrm{bp}$ of the gene, whereas the second represented the last $419 \mathrm{bp}$ of the mutL gene (Fig. 1). The ensuing plasmid, pFG2791, was linearized with $K p n I$ and used to transform competent cells of strain PB1831, selecting for $\mathrm{Cm}^{\mathrm{R}}$. The chromosomal DNA of the transformants was analysed by HindIII digestion and Southern hybridization with a suitable
Table 3. Spontaneous frequencies of mutation of parental and mutSL-deleted strains

\begin{tabular}{|c|c|c|}
\hline Strain & & Frequency of $\mathbf{R f}^{\mathbf{R}}$ mutants \\
\hline \multirow[t]{3}{*}{ PB1831 (parental) } & Exp. 1 & $0.22 \times 10^{-6}$ \\
\hline & Exp. 2 & $0.08 \times 10^{-6}$ \\
\hline & Exp. 3 & $0.05 \times 10^{-6}$ \\
\hline \multirow[t]{4}{*}{ PB1856 (AmutSL::cat) } & Exp. 1 & $14 \cdot 1 \times 10^{-6}$ \\
\hline & Exp. 2 & $3.7 \times 10^{-6}$ \\
\hline & Exp. 3 & $4 \cdot 6 \times 10^{-6}$ \\
\hline & \multicolumn{2}{|r|}{ Frequency of $\mathrm{Phe}^{+}$revertants } \\
\hline PB1831 (parental) & & $0.6 \times 10^{-8}$ \\
\hline \multirow[t]{2}{*}{ PB1856 (dmutSL: : cat) } & & $9 \cdot 9 \times 10^{-8}$ \\
\hline & & 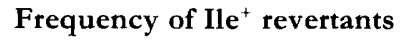 \\
\hline PB1868 (parental) & & $0 \cdot 46 \times 10^{-6}$ \\
\hline 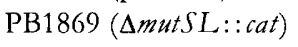 & & $8 \cdot 0 \times 10^{-6}$ \\
\hline
\end{tabular}

probe. One deletion-bearing strain (PB1856) was used to test the role of the two genes in preventing, through mismatch repair, the accumulation of mutations. We compared the spontaneous mutation rate of strain PB1831 to that of PB1856. We found that in the mutant strain the frequency of rifampicin-resistant $\left(\mathrm{Rf}^{\mathrm{R}}\right)$ mutants was from 40-60 times higher than that observed for the parental strain (Table 3). To further confirm the role of mut $S$ and mut $L$, we compared the reversion of phenylalanine auxotrophy between the two strains. The number of $\mathrm{Phe}^{+}$ revertants in strain PB1856 was 16.5-fold greater than that of the control strain (Table 3 ). In addition, colonies of strain PB1856 showed an altered morphology on SM. Transparent sectors were clearly visible after $2-3 \mathrm{~d}$ incubation, suggesting the formation of sporulationdeficient clones.

An increase in the number of revertants was also observed for the ilvC1 marker, when present in a mutSL-deleted background (Table 3 ). The $\operatorname{trp} C 2$ and met $B 4$ markers were not affected in their reversion by the absence of the mismatched repair system (data not shown).

In addition to the mutator phenotype, Strep. pneumoniae bex mutants show identical transformation efficiencies for different markers that in the wild-type strain have different frequencies of transformation, due to the different molecular basis of the mutation characterizing the marker and consequently the heteroduplex molecule produced during recombination (Lacks, 1970).

We tested for such a phenotype associated with the mutSL deletion in B. subtilis. We choose two markers (ilvC1 and metB4) which were previously shown to give different relative frequencies of transformation, probably due to the differences in the efficiency of integration of the donor marker into the chromosome (Barat et al., 1965). The ilv C1 marker, at a non-saturating DNA concentration, is transformed less efficiently than the metB4 marker. In mutSL-deleted strains, the two markers are transformed with the same efficiency (Table 4), supporting the concept 
Table 4. Frequency of transformation of ilvC1 and metB4 markers relative to $\operatorname{trp} C 2$

The pairs of numbers refer to the results of two independent experiments.

\begin{tabular}{|lcc|}
\hline Marker & mutSL & smutSL* \\
\hline ilvC1 & $0.38,0.33$ & $1 \cdot 20,0.87$ \\
metB4 & $1 \cdot 00,1.43$ & $0.90,0.91$ \\
\hline
\end{tabular}

* The ratio was calculated after subtraction of the background due to reversion.

that different efficiencies of integration are caused by the discrimination targeted to the incoming donor strand by the mismatch repair system recognizing certain types, and not others, of heteroduplex.

\section{Expression of the mutSL operon}

To study the expression of the mut operon, we constructed a mut-lacZ fusion. A 333 bp fragment containing the mutS promoter region was amplified via PCR and cloned upstream of a promoterless E. coli lac $Z$ gene in the expression vector pDH32 (Shimotsu \& Henner, 1986). The plasmid obtained (pFG2783S) was used after linearization to transform strain PB1831. Stable double crossover integrants in the amy $E$ locus were checked for an inability to degrade starch. $\beta$-Galactosidase assays were then performed with the new strain using different media.

In rich media (SM or PY) the mut operon is constitutively expressed during vegetative growth. While the cells undergo sporulation, the gene is progressively turned off (data not shown). The levels of expression are in general rather low: the $\beta$-galactosidase levels never exceeded 60 Miller units. Growth in minimal medium showed an interesting aspect. A slight increase in expression was constantly observed when the culture entered stationary phase at about $t_{-1}$ (Fig. 5). This may be interpreted as due to the fraction of cells entering the competent state. An active mismatch repair complex may be required during the competent phase to prevent mispairing and it could be responsible for the observed correction of heteroduplexes in the course of transformation (Bresler et al., 1968).

The possible correlation between the increased expression of mutSL and competence deserves further investigation, especially in consideration of the reported lack of induction of mismatch repair genes in competent cells of Strep. pneumoniae (Humbert et al., 1995).

Expression of the mut-lac $Z$ fusion was studied in various mutant backgrounds. It was not affected by deletion of $\operatorname{comK}$ or $\operatorname{com} A-P$ which encode regulatory proteins of late competence genes. In a $\operatorname{rec} A$ mutant strain the expression was not affected during exponential growth, whereas the subsequent decrease observed during stationary phase was relieved and the level of $\beta$-galactosidase remained constant until $4 \mathrm{~h}$ after $t_{0}$ (Fig. 5). This observation

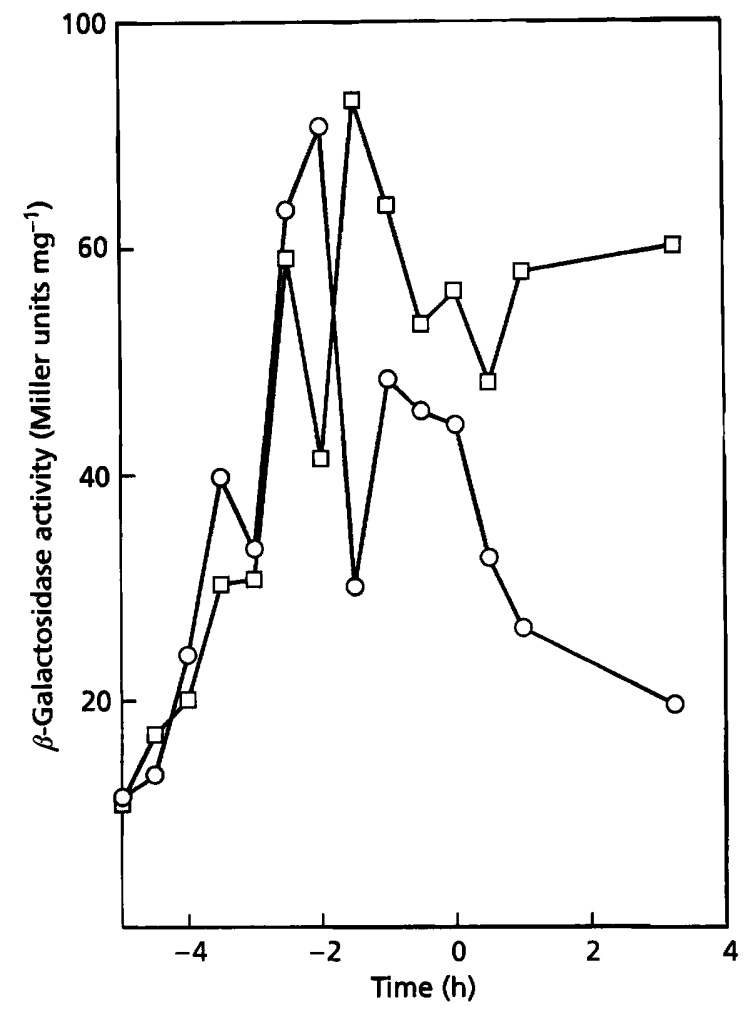

Fig. 5. Expression of mutSL-lacZ fusion. The specific activity of $\beta$-galactosidase was monitored in minimal medium in a wildtype strain $(O)$ or in a recA mutant $(\square)$ carrying a mutSL-lacZ transcriptional fusion at the amyE locus.

suggests a possible regulatory role of the RecA protein on the expression of the mismatch repair system. At present we cannot discriminate between a direct or indirect effect of the $\operatorname{rec} A$ mutation.

The fact that the mismatch repair system is not constitutively expressed but may be under genetic and physiological control, could shed some light on diverse phenomena such as adaptive mutation and spontaneous mutation accumulations in cancers (Longerich et al., 1955).

\section{ACKNOWLEDGEMENTS}

We thank Lingbiae Zheng for kindly providing plasmid pLZ100. This work was supported in part by the European Commission under the Biotechnology programme (contract Bio2-CT93-0272) and by Consiglio Nazionale delle Ricerche (Grants 92.02183.CT 174 AND 93.02009.CT14).

\section{REFERENCES}

Alani, E., Reenan, R. A. G. \& Kolodner, R. (1994). Interaction between mismatch repair and genetic recombination in Saccharomyces cerevisiae. Genetics 137, 19-39.

Albertini, A. M. \& Galizzi, A. (1990). The Bacillus subtilis outB gene is highly homologous to an Escherichia coli ntr-like gene. J Bacteriol 172, 5482-5485.

Altschul, S. F., Gish, W., Miller, W., Myers, E. W. \& Lipman, D. J. (1990). Basic Local Alignment Search Tool. J Mol Biol 215, 403-410. 
Barat, M., Anagnostopoulos, C. \& Schneider, A.-M. (1965). Linkage relationships of genes controlling isoleucine, valine and leucine biosynthesis in Bacillus subtilis. J Bacteriol 90, 357-369.

Bresler, S. E., Kreneva, R. A. \& Kushev, V. V. (1968). Correction of molecular heterozygotes in the course of transformation. Mol Gen Genet 102, 257-268.

Bronner, C. E. and others (1994). Mutation in the DNA mismatch repair gene homologue hMLH1 is associated with hereditary nonpolyposis colon cancer. Nature 368, 258-261.

Claverys, J. P. \& Lacks, S. A. (1986). Heteroduplex deoxyribonucleic acid base mismatch repair in bacteria. Microbiol Rev 50, 133-165.

Connoly, D. M. \& Winkler, M. E. (1992). Structure of Escherichia coli $\mathrm{K} 12$ mia. $A$ and characterization of the mutator phenotype caused by mia.A insertion mutations. J Bacteriol 173, 1711-1721.

Ferrari, F. A., Nguyen, A., Lang, D. \& Hoch, J. A. (1983). Construction and properties of an integrable plasmid for Bacillus subtilis. J Bacteriol 154, 1513-1515.

Fishel, R., Lescoe, M. K., Rao, M. R. S., Copeland, N. G., Jenkins, N. A., Gaber, J., Kane, M. \& Kolodner, R. (1993). The human mutator gene homolog MSH2 and its association with hereditary nonpolyposis colon cancer. Cell 75, 1027-1038.

Glaser, P. and others (1993). Bacillus subtilis genome project: cloning and sequencing of the $97 \mathrm{~kb}$ region from $325^{\circ}$ to $333^{\circ}$. Mol Microbiol 10, 371-384.

Haber, L. T., Pang, P. P., Sobell, D. I., Mankovich, J. A. \& Walker, G. C. (1988). Nucleotide sequence of the Salmonella typhimurium mut $S$ gene required for mismatch repair: homology of MutS and HexA of Streptococcus pneumoniae. J Bacteriol 170, 197-202.

Hoch, J. A., Barat, M. \& Anagnostopoulos, C. (1967). Transformation and transduction in recombination-defective mutants of Bacillus subtilis. J Bacteriol 93, 1925-1937.

Humbert, O., Prudhomme, M., Hakenbeck, R., Dowson, C. G. \& Claverys, J. P. (1995). Homologous recombination and mismatch repair during transformation in Streptococcus pneumoniae: saturation of the Hex mismatch repair system. Proc Natl Acad Sci US.A 92, 9052-9056.

Kramer, W., Kramer, B., Williamson, M. S. \& Fogel, S. (1989). Cloning and nucleotide sequence of DNA mismatch repair gene PMS-1 from Saccharomyces cerevisiae: homology of PMS-1 to procaryotic MutL and HexB. J Bacteriol 171, 5339-5346.

Lacks, S. (1970). Mutants of Diplococcus pneumoniae that lack deoxyribonucleases and other activities possibly pertinent to genetic transformation. J Bacteriol 101, 373-383.

Le, O., Shen, B., lismaa, S. E. \& Burgess, B. K. (1993). Azotobacter vinelandii mutS: nucleotide sequence and mutant analysis. J Bacteriol $175,7707-7710$

Leach, F. S. and others (1993). Mutations of a mutS homolog in hereditary nonpolyposis colorectal cancer. Cell 75, 1215-1225.

Longerich, S., Galloway, A. M., Harris, R. S., Wong, C. \& Rosenberg, S. M. (1995). Adaptive mutation sequences reproduced by mismatch repair deficiency. Proc Natl Acad Sci US A 92, $12017-$ 12020 .

Mankovich, J. A., Mcintyre, C. A. \& Walker, G. C. (1989). Nucleotide sequence of the Salmonella typhimurium mut $L$ gene required for mismatch repair: homology of MutL and HexB of Streptocaccus pneumoniae and to PMS1 of the yeast Saccharomyces cerevisiae. I Bacteriol 171, 5325-5331.

Modrich, P. (1991). Mechanisms and biological effects of mismatch repair. Annu Rev Genet 25, 229-253.

Modrich, P. (1994). Mismatch repair, genetic stability, and cancer. Science 266, 1959-1960.
Nicolaides, N. C. and others (1994). Mutations of two PMS homologues in hereditary nonpolyposis cancer. Nature 371, 75-80. Papadopoulos, N. and others (1994). Mutation homolog in hereditary colon cancer. Science 263, 1625-1629.

Pearson, W. R. (1990). Rapid and sensitive sequence comparison with Fastr and Fasta. Metbods Enzymol 183, 63-98.

Perego, M. (1993). Integrational vectors for genetic manipulations in Bacillus subtilis. In Bacillus subtilis and Other Gram-positive Bacteria, pp. 615-624. Edited by A. L. Sonenshein, J. A. Hoch \& R. Losick. Washington, DC: American Society for Microbiology.

Petit, M. A., Dimpfl, J., Radman, M. \& Echols, H. (1991). Control of large chromosomal duplications in Escherichia coli by the mismatch repair system. Genetics $129,327-332$.

Priebe, S. D., Hadi, S. M., Greenberg, B. \& Lacks, S. A. (1988). Nucleotide sequence of the bex.A gene for mismatch repair in Streptococcus pneumoniae and homology of HexA to MutS of Escherichia coli and Salmonella typhimurium. J Bacteriol 170, 190-196.

Prudhomme, M., Martin, B., Méjean, V. \& Claverys, J. P. (1989). Nucleic acid sequence of the Streptococcus pneumoniae bex $B$ mismatch repair gene: homology of HexB to MutL of Salmonella typhimurium and to PMS1 of Saccharomyces cerevisiae. J Bacteriol 171, 5332-5338.

Prudhomme, M., Méjean, V., Martin, B. \& Claverys, J. P. (1991). Mismatch repair genes of Streptococius pneumoniae: HexA confers a mutator phenotype in Escherichia coli by negative complementation. J Bacteriol 173, 7196-7203.

Rayssiguier, C., Thaler, D. \& Radman, M. (1989). The barrier to recombination between Escherichia coli and Salmonella typhimurium is disrupted in mismatch-repair mutants. Nature 342, $396 \cdots 401$.

Reenan, R. A. G. \& Kolodner, R. D. (1992). Isolation and characterization of two Saccharomyces cerevisiae genes encoding homologs of the bacterial HexA and MutS mismatch repair proteins. Genetics 132, 963-973.

Sambrook, J., Fritsch, E. F. \& Maniatis, T. (1989). Molecular Cloning: a Laboratory Manual. Cold Spring Harbor, NY: Cold Spring Harbor Laboratory.

Schaeffer, P., Millet, J. \& Aubert, J. (1965). Catabolite repression of bacterial sporulation. Proc Natl Acad Sci US A 54, 704-711.

Schlensong, V. \& Boeck, A. (1991). The Escherichia coli $f d$ ' gene probably encodes MutS and is located at minute 58.8 adjacent to byc-byp gene cluster. J Bacteriol 173, 7414-7415.

Shimotsu, H. \& Henner, D. J. (1986). Construction of a single-copy integration vector and its use in analysis of regulation of the trp operon of Bacillus subtilis. Gene 43, 85 94.

Thompson, J. D., Higgins, D. G. \& Gibson, T. J. (1994). Clustal w: improving the sensitivity of progressive multiple sequence alignment through sequence weighting, position-specific gap penalties and weight matrix choice. Nucleic. Acids Res 22, 4673-4680.

Worth, L., Clark, S., Radman, M. \& Modrich, P. (1994). Mismatch repair proteins MutS and MutL inhibit RecA-catalyzed strand transfer between diverged DNAs. Proc Natl Acad Sci USA 91, 3238-3241.

Zheng, L., Donovan, W. P., Fitz-James, P. C. \& Losick, R. (1988). Gene encoding a morphogenetic protein required in the assembly of the outer coat of the Bacillus subtilis endospore. Genes Dev 2, 1047-1054.

Received 3 October 1995; revised 28 February 1996; accepted 11 March 1996. 